\title{
Erratum to "Empirical Equation for the Gravitational Constant with a Reasonable Temperature" [Journal of Modern Physics 11 (2020) 1180-1192]
}

\section{Tomofumi Miyashita}

Miyashita Clinic, Osaka, Japan

Email:tom_miya@plala.or.jp

Received: September 27, 2020

Accepted: October 13, 2020

Published: October 16, 2020

Copyright $\odot 2020$ by author(s) and Scientific Research Publishing Inc. This work is licensed under the Creative Commons Attribution International License (CC BY 4.0).

http://creativecommons.org/licenses/by/4.0/
The original online version of this article (Miyashita, T. (2020) Empirical Equation for the Gravitational Constant with a Reasonable Temperature. Journal of Modern Physics, 11, 1180-1192. https://dx.doi.org/10.4236/jmp.2020.118074) unfortunately contains the very important mistakes. The calculated temperature was $2.7195 \mathrm{~K}$, which is similar to the temperature of the cosmic microwave background $2.7254 \mathrm{~K}$.

\subsection{Our Empirical Equation}

Our empirical equation is quoted from Wikipedia.

https://en.wikipedia.org/wiki/Proton

$$
\frac{G m_{p}}{\frac{\lambda_{p}}{2}} \times 1 \mathrm{~kg}=\frac{9}{2} k T
$$

$G$ : gravitational constant, $6.6743 \times 10^{-11}\left(\mathrm{~m}^{3} \cdot \mathrm{kg}^{-1} \cdot \mathrm{s}^{-2}\right)$

$m_{p}$ : the rest mass of a proton, $1.6726 \times 10^{-27}(\mathrm{~kg})$

$r_{p}$ : charge radius, $8.41 \times 10^{-16}(\mathrm{~m})$ (We must not use this value.)

Ip: Compton wavelength $1.321409 \times 10^{-16}(\mathrm{~m})$

$k$. Boltzmann constant, $1.380649 \times 10^{-23}(\mathrm{~J} / \mathrm{K})$

T: temperature $(\mathrm{K})$

$1 \mathrm{~kg}$ : the standard mass $(\mathrm{kg})$

The temperature calculated using this formula was $2.71953 \mathrm{~K}$, which is similar to the temperature of the cosmic microwave background of $2.72548 \mathrm{~K}$. We must use the half of Compton wavelength. The proton consists of three quarks. Then, we must consider $9 / 2 \mathrm{k} T$ and not $3 \mathrm{k} T$. But the main theory can be unchanged. 